ISSN: $2450-6869$

eISSN: $2719-6763$

DEFENCE SCIENCE REVIEW

http://www.journalssystem.com/pno/

No. 10,2020

DOI: $10.37055 / \mathrm{pno} / 139976$

\title{
Contemporary indicators of security. An attempt to measure the level of security.
}

\section{Original article}

Received: 2021-06-13

Revised: 2021-07-04

Accepted: 2021-07-05

Final review: 2021-07-04

\section{Peer review:}

Double blind

\section{Keywords:}

security, security threats, security indicators, security measurement

This work is licensed under the Creative Commons AttributionNonCommercial-NoDerivatives 4.0 License

\author{
Radosław Bielawski ${ }^{1, D}$ \\ ORCID (D) 0000-0002-5701-4476
}

\author{
${ }^{1}$ Military University of Technology, Poland
}

A - Research concept and design, B - Collection and/or assembly of data, C - Data analysis and interpretation, D - Writing the article, E - Critical revision of the article, F - Final approval of article

\section{Abstract}

Objectives: The subject of consideration in this article are contemporary indicators of security, which allow to determine its level in quantifiable values.

Methods: For the purposes of this research, the following research methods were applied: analysis, synthesis, generalisation and inference.

Results: This paper is a review of selected powermetric studies on security, which were divided into global studies estimating state power such as: Global Firepower Report, 2021 Measuring National and Power Index of the power of states and their indicators - area-specific studies, which prove to be increasingly useful due to growing cyber threats or threats related to the current COVID-19 pandemic. The so-called doomsday clock was selected as an indicator of international security, in which individual hours define the level of security, with midnight indicating the annihilation of humanity. In addition to models for estimating security and state power, on the basis of the results of the studies cited, the paper also mentions possible directions for further development of threats and recommendations in this regard.

Conclusions: The research results presented in the analysed studies are useful for estimating various types of security indicators, both in terms of state security, as well as various other aspects of security, including health, soft power or cyber security. Security indicators can be used by analysts, politicians, decision-makers, and other entities involved in security management as a source of knowledge and measurable values determining the level of security and threats. They also help to indicate weaknesses in security systems in order to quickly diagnose and eliminate them. 


\section{Introduction}

Security sciences deal with the widely understood phenomenon of security, drawing from numerous other areas of science, such as: the humanities, social sciences, engineering and technology, medicine, mathematical and natural sciences and others. For this reason, they are often described as interdisciplinary or multidisciplinary sciences. Despite the considerable interest in this discipline, the literature on the subject still lacks structured knowledge presented in quantifiable terms, which would make it useful and practically applicable both in the area of security sciences and in other scientific disciplines. Calculated numerical values estimating state and other types of security may constitute a basis for analysts, statisticians, forecasters and other researchers dealing with security.

The aim of this review article is to present and systematise selected studies that offer quantifiable results. The author attempts to answer the question of how and with what tools can security be estimated in terms of quantifiable values. In order to achieve the research objective and answer the research question, the theoretical research methods of analysis, synthesis, generalisation and inference were used.

\section{Powermetric rankings and reports}

One type of studies estimating the power of states are powermetric reports and rankings, which describe and estimate in an analytical way various types of indicators. These studies use powermetric models, which are based on mathematical relationships, usually defining the power (strength) of a state in a quantifiable way. The models usually contain several powermetric factors, including scientific, technical, economic, social, political, cultural and military one. The factors are usually assigned variables and weights. The weights, factors and variables are usually determined through surveys, the use of the delphi method and the factor analysis method. This allows to obtain quantifiable values of variables and then reduce the variables in order to optimise the model. Respondents in this type of surveys are usually experts in the field.

An example of a powermetric study is an online compilation - the Global Firepower Report (Global Firepower 2021, 2021). State assessment in this study is based on 8 factors and 50 variables assigned to them, and the powermetric factors adopted include: manpower, airpower, land forces, naval forces, natural resources, logistics, economics and geography. The first three factors are determined by quantitative indicators of available armaments and military equipment: aircraft, tanks, armoured vehicles and naval fleet (mainly ships and submarines). Natural resources and economics are estimated by taking into account values 
such as the state defence budget, external debt, purchasing power parity (PPP) and the amount of foreign currency and gold reserves. State logistics, in turn, is assessed based on such indicators as the number of airports, labour force, number of major ports and trade terminals, size of the merchant fleet, total length of railways, roads and highways. The geography factor is shaped by such elements as the country's surface area, as well as the length of: the state border, coastline and waterways. One of the assessment methods used by the Global Firepower Report is the possibility of creating and comparing two coalitions.

Each can consist of a maximum of seven actors. The idea behind such a comparison is to determine and estimate the power of various alliances for different types of armed conflicts.

Based on the factors and variables, the so-called PowerIndex (PwrIndx) is determined - a quantified index inversely proportional to the value of the power of a given state. The results for selected countries according to the Global Firepower 2021 Report are summarised in the table below (Table 1).

Another study that examines the issue of state power is Measuring National Power (Treverton et al., 2005) published by the RAND Corporation. This study assesses the power of states taking into account selected capabilities: economic, demographic, technological and military/combat capability. The following elements were used as indicators: GDP, population, defence spending, technological innovations. In addition, the model takes into account the possession of nuclear weapons by states. The report analyses both state actors (international balance of power) and non-state entities - international organisations such as: United Nations, World Bank or World Trade Organization. State power scores of selected state actors are presented in the table below (Table 1).

Another powermetric study is the National Power Index (Arak et al., 2018). It was released twice in 2017 and 2018 and has not been updated ever since. The study presents the international balance of power since 1991. The adopted original model calculates state power on the basis of the so-called seven power dimensions, which are the basic powermetric factors of the model. These include: economic capital (based on GDP), the country's rating and the number of millionaires. Another factor - militarisation - is estimated on the basis of such factors as military expenditure, production and sales of arms, the number of uniformed services and the possession of nuclear weapons. In terms of the geographic-demographic factor, such elements as the area of the country, as well as the size of the population and the number of people $65+$ are taken into account. The natural resources factor is assessed on the basis of energy import/export data, as well as revenues from raw material extraction in relation to GDP. The model included in the index also includes soft power elements - culture 
and diplomacy. Culture is assessed by the number of universities listed on the Shanghai list and the number of trademarks registered with WIPO (World Intellectual Property Organization). In turn, diplomacy is calculated on the basis of three sub-indicators, which consist of a given country's membership in: UN Security Council, major international organisations and chairmanship of international organisations. State power scores according to the National Powe Index are summarised in the table below (Table 1). 
Table 1. Ranking of selected states according to selected powermetric reports and rankings (Global Firepower 2021, 2021; Treverton et al., 2005; Arak et al., 2018)

\begin{tabular}{|c|c|c|c|c|c|c|}
\hline \multirow{2}{*}{ position } & \multicolumn{2}{|c|}{ Global Firepower Report 2021} & \multicolumn{2}{|c|}{ Measuring National Power } & \multicolumn{2}{|c|}{ National Power Index } \\
\hline & state & PwrIndx & state & score $(\%)$ & state & number of points \\
\hline 1 & United States & 0.0718 & United States & 20 & European Union & 17.53 \\
\hline 2 & Russian Federation & 0.0791 & European Union & 14 & United States & 16.65 \\
\hline 3 & $\begin{array}{c}\text { People's Republic of } \\
\text { China }\end{array}$ & 0.0854 & $\begin{array}{c}\text { People's Republic of } \\
\text { China }\end{array}$ & 14 & $\begin{array}{c}\text { People's Republic of } \\
\text { China }\end{array}$ & 14 \\
\hline 4 & India & 0.1207 & India & 9 & India & 5.33 \\
\hline 5 & Japan & 0.1599 & Russian Federation & 2 & Russian Federation & 5.29 \\
\hline 6 & South Korea & 0.1612 & South Korea & 2 & Germany & 3.05 \\
\hline 7 & France & 0.1681 & Brazil & 2 & France & 2.80 \\
\hline 8 & United Kingdom & 0.1997 & - & - & United Kingdom & 2.73 \\
\hline 9 & Brazil & 0.2026 & - & - & Japan & 2.57 \\
\hline 10 & Pakistan & 0.2073 & - & - & Brazil & 2.45 \\
\hline - & (23rd) Poland & 0.4187 & - & - & (26th) Poland & 0.66 \\
\hline
\end{tabular}




\section{Area-specific indicators of security}

Security studies with quantified results also include area-specific studies, which deal with a particular security sub-discipline. An example is the Global Health Security Index (Mutschler and Bales, 2020). It concerns health security (Marton, 2020, p. 2; Masys et al., 2020; Boyce et al., 2021, p. 181) and is particularly useful in view of the current COVID-19 pandemic (Szymanski, Smuniewski and Platek, 2020). The index contains estimates for 195 countries. The purpose of this study is to identify critical points in terms of a given country's readiness and capability to respond to health security threats, including pandemics.

The methodology of the index was developed by 21 experts from 13 countries who came up with 140 questions, categorised into 34 indicators (variables), 85 sub-indicators and | 6 categories: prevention, detection and reporting, rapid response, health system, compliance with international norms and risk environment. These are summarised in the table below (Table 2).

Table 2. Factors and variables in the Global Health Security Index model (Mutschler et al., 2020, p. 8)

\begin{tabular}{|c|c|c|c|}
\hline Factor & Description & $\begin{array}{l}\text { Number } \\
\text { of } \\
\text { variables }\end{array}$ & Types (description) of variables \\
\hline prevention & $\begin{array}{c}\text { prevention of the } \\
\text { emergence or release of } \\
\text { pathogens }\end{array}$ & 6 & $\begin{array}{l}\text { - antimicrobial resistance (AMR) } \\
\text { - zoonotic disease } \\
\text { - biosecurity, biosafety } \\
\text { - dual use research and culture of } \\
\text { responsible science } \\
\text { - immunisation }\end{array}$ \\
\hline $\begin{array}{l}\text { detection and } \\
\text { reporting }\end{array}$ & $\begin{array}{l}\text { early detection and } \\
\text { reporting for epidemics of } \\
\text { potential international } \\
\text { concern }\end{array}$ & 4 & $\begin{array}{l}\text { - laboratory systems } \\
\text { - real time surveillance and reporting } \\
\text { - epidemiology workforce } \\
\text { - data integration between } \\
\text { human/animal/environmental health } \\
\text { sectors }\end{array}$ \\
\hline rapid response & $\begin{array}{c}\text { rapid response to and } \\
\text { mitigation of the spread of } \\
\text { an epidemic }\end{array}$ & 7 & $\begin{array}{l}\text { - emergency preparedness and response } \\
\text { planning } \\
\text { - exercising response plans } \\
\text { - emergency response operation } \\
\text { - linking public health and security } \\
\text { authorities } \\
\text { - risk communication } \\
\text { - access to communications infrastructure } \\
\text { - trade and travel restrictions }\end{array}$ \\
\hline health system & $\begin{array}{l}\text { sufficient and robust health } \\
\text { system to treat the sick and } \\
\text { protect health workers }\end{array}$ & 6 & $\begin{array}{l}\text { - health capacity in clinics, hospitals and } \\
\text { community care centres } \\
\text { - medical countermeasures and personnel } \\
\text { deployment } \\
\text { - healthcare access } \\
\text { - communications with healthcare workers }\end{array}$ \\
\hline
\end{tabular}




\begin{tabular}{|c|c|c|c|}
\hline & & & $\begin{array}{l}\text { during a public health emergency } \\
\text { - infection control practices and } \\
\text { availability of equipment } \\
\text { - capacity to test and approve new medical } \\
\text { countermeasures }\end{array}$ \\
\hline $\begin{array}{c}\text { compliance with } \\
\text { international } \\
\text { norms }\end{array}$ & $\begin{array}{l}\text { commitments to improving } \\
\text { national capacity, } \\
\text { financing plans to address } \\
\text { gaps, and adhering to } \\
\text { global norms }\end{array}$ & 6 & $\begin{array}{l}\text { - International Health Regulations (IHR) } \\
\text { reporting compliance and disaster risk } \\
\text { reduction } \\
\text { - cross-border agreements on public health } \\
\text { emergency response } \\
\text { - international commitments } \\
\text { - Joint External Evaluation (JEE) and } \\
\text { Performance of Veterinary Services } \\
\text { (PVS) } \\
\text { - financing } \\
\text { - commitment to sharing of genetic and } \\
\text { biological and specimens }\end{array}$ \\
\hline risk environment & $\begin{array}{l}\text { overall risk environment } \\
\text { and country vulnerability } \\
\text { to biological threats }\end{array}$ & 5 & $\begin{array}{l}\text { - political and security risk } \\
\text { - socio-economic resilience } \\
\text { - infrastructure adequacy } \\
\text { - environmental risks } \\
\text { - public health vulnerabilities }\end{array}$ \\
\hline
\end{tabular}

The results of the report are presented in the form of a ranking with numerical values of the index (maximum value of 100) and three categories of preparedness of the states - most prepared, more prepared and least prepared. The results for selected countries are presented in the table below (Table 3).

Table 3. Global Health Security Index - selected states ranking (as of: 20 April 2021) (2019 Global Health Security Index, 2021)

\begin{tabular}{|c|c|c|c|}
\hline rank & country & index score & preparation \\
\hline 1 & United States & 83.5 & most prepared \\
\hline 2 & United Kingdom & 77.9 & most prepared \\
\hline 3 & Netherlands & 75.6 & most prepared \\
\hline 4 & Australia & 75.5 & most prepared \\
\hline 5 & Canada & 75.3 & most prepared \\
\hline 6 & Thailand & 73.2 & most prepared \\
\hline 7 & Sweden & 72.1 & most prepared \\
\hline 8 & Denmark & 70.4 & most prepared \\
\hline 9 & South Korea & 70.2 & most prepared \\
\hline 10 & Finland & 68.7 & most prepared \\
\hline 32 & Poland & 55.4 & more prepared \\
\hline
\end{tabular}

The Global Health Security Index report also allows to show statistics for a selected region or country, with five categories and all variables included. It is possible to verify a 
given country's place in the ranking, both for the whole index and for individual categories and variables. The ranking also enables a comparison of three selected countries or regions, for which results are generated both for the whole index as well as for the 6 categories separately.

Another form of presenting data in the index is a graphic map (the so-called heatmap), with individual countries coloured according to the previously mentioned preparedness level. Results can be generated both for the whole index, as well as for each factor or variable separately. The heatmap below shows results for the whole index (Fig. 1).

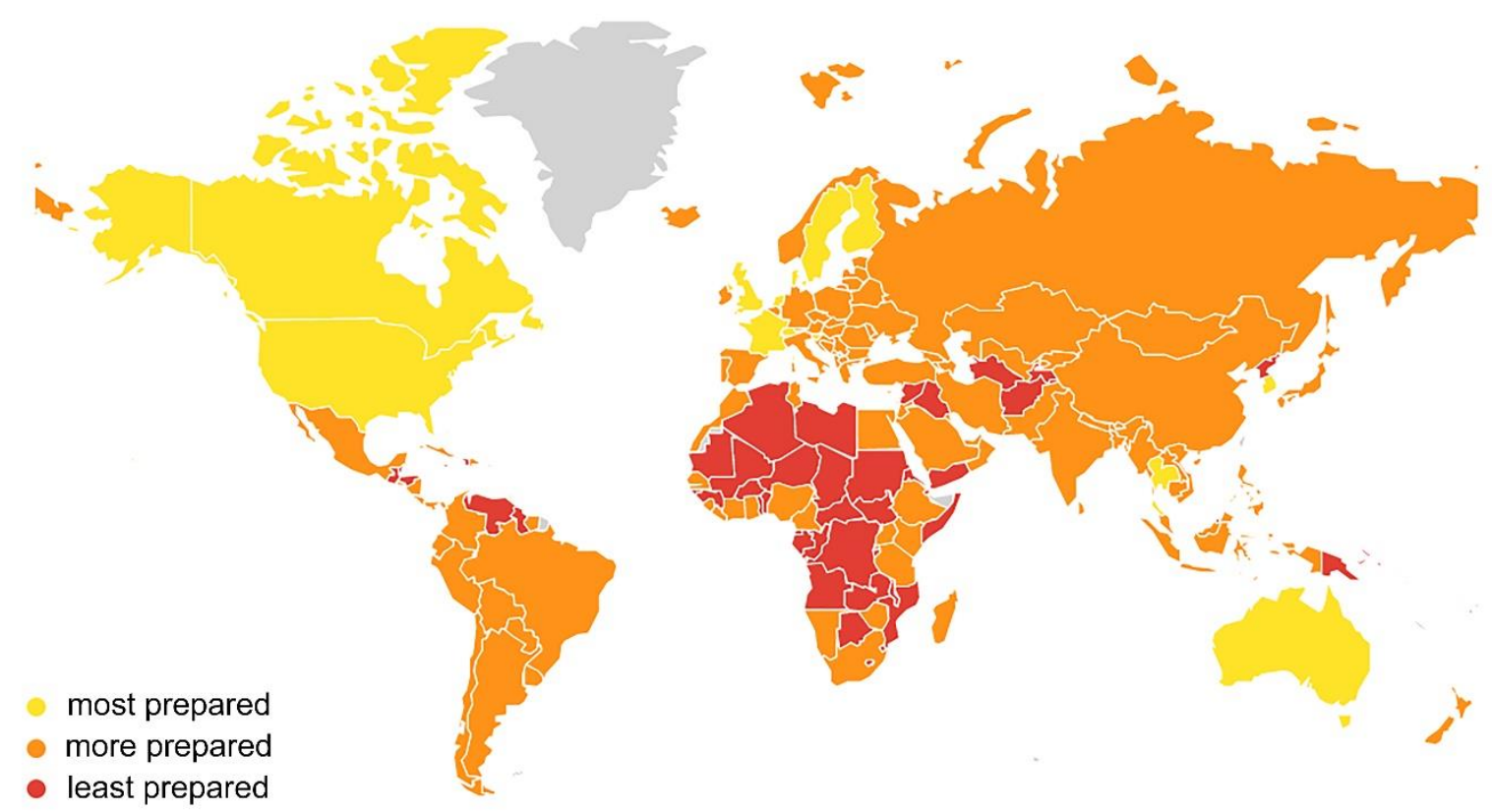

Fig. 1. Heatmap - GHS Index Map (as of: 20 April 2021) (2019 Global Health Security Index, 2021)

Analysing the results presented in this study, it can be concluded that most countries have a low level of preparedness for pandemics or epidemics. The average overall GHS Index score among all 195 countries examined is 40.2 (the maximum value being 100 points) (2019 Global Health Security Index, 2021). Given the poor results, the report provides in addition guidelines and recommendations aimed at increasing the level of health security of countries and regions. It recommends monitoring and self-assessment of the national/regional level of health security at least once every two years. Another recommendation is to implement new mechanisms of financing global health security, as well as allow for the possibility to use funds of supporting organisations, such as World Bank International Development Association (IDA). 
Another area-specific study is the Soft Power Ranking 30 (Jonathan, 2019; Soft Power $30,2021)$. It presents the results for soft power, estimating the power of a entities and states on the basis of such factors as: culture, ideology and state institutions (Zhang, 2017; Bielawski et al., 2020; Ohnesorge, 2020). The University of Southern California's Center on Public Diplomacy (CPD), established in 2003 as the world's first institution dealing with soft power, public diplomacy (Uysal and Schroeder, 2019) and international cultural relations, supports the initiative (USC Center on Public Diplomacy, 2021).

The ranking is based on surveys conducted in 25 countries (including all G20 countries). Each country surveyed designated 500 respondents, which gave a total sample size of 12,500. The questionnaire contained an 11-point scale (from 0 to 10) - from the most negative to the most positive responses. The survey was conducted between 24 July and 2 August 2019. Further estimates were based on two types of factors deteremined by a regression model - objective data $(65 \%)$, polling data $(35 \%)$ and the variables assigned to them (Table 4).

Table 4. Factors and variables used in the Soft Power 30 ranking (Jonathan, 2019, p. 11)

\begin{tabular}{|c|c|c|c|}
\hline \multirow{2}{*}{ variable type } & variable share & $\begin{array}{c}\text { number of variable } \\
\text { factors }\end{array}$ & polling data (35\%) \\
\hline government & $20.8 \%$ & 16 & technology products \\
\hline digital & $13.1 \%$ & 10 & friendliness \\
\hline culture & $12.5 \%$ & 13 & culture \\
\hline enterprise & $18.7 \%$ & 12 & luxury goods \\
\hline engagement & $20.6 \%$ & 12 & foreign policy \\
\hline education & $14.3 \%$ & 5 & liveability \\
\hline
\end{tabular}

When calculating the values for individual actors, the methodology of effective use of soft power, based on Joseph Nye's model, was used. It consists of five consecutive steps: resources, objectives, conversion, target response, outcome (Nye, 2011; Marklund, 2020).

The report addresses the issues of the so-called international order, defined as: a combined set of rules, norms, values, institutions, security agreements, treaties and other mechanisms that foster cooperation and help resolve disputes between states (Mazarr et al., 2016). As disruption of the international order has a direct impact on national security, the report suggests theoretical strategies for maintaining a high level of international security. These strategies can be divided into three types. The first one is referred to as "retrenchment" and mainly concerns the position and involvement of the United States in international 
security issues. The strategy consists in reducing US involvement in international security and withdrawing US military resources from areas beyond its territory. In practice, this would also entail reducing global ambitions of the US and removing the country from the position of a leader in terms of key international issues. The strategy would also force the United States of America to rebuild and professionalise its diplomatic corps, as well as update its diplomatic doctrine, mainly in terms of the use of noncoercive means of influence. Another strategy to maintain a high level of the international security index is "consolidation". It consists in consolidating the capabilities gained over the last decades. The main idea of this approach is to make states focus on their internal affairs rather than pursue an expansionist policy. The third strategy is "expansive reinforcement", and its aim is strengthening and promoting liberalism and multilateralism. This strategy assumes a revival of the liberal international order, which would require the introduction of policies encouraging tolerance, independence and integrity of the media, critical thinking and respect for human rights. In terms of international policies, this strategy advocates an effective cooperation between leading liberal states and forcible restraint of illiberal states that undermine the international order. Another step in this approach would involve a concentrated effort to transform a greater number of neutral or transition states into liberal states. In practical terms, this would require increased promotion of democracy, respect for human rights, and encouragement of political reform.

The results of the Soft Power 30 ranking for selected state actors, along with their scores, are presented in the table below (Table 5).

Table 5. Soft Power 30 Index - selected states ranking (as of: 13 May 2021)

(Jonathan, 2019, pp. 37-38)

\begin{tabular}{|c|c|c|}
\hline rank & country & score \\
\hline 1 & France & 80.28 \\
\hline 2 & United Kingdom & 79.47 \\
\hline 3 & Germany & 78.62 \\
\hline 4 & Sweden & 77.41 \\
\hline 5 & United States & 77.40 \\
\hline 6 & Switzerland & 77.04 \\
\hline 7 & Canada & 75.89 \\
\hline 8 & Japan & 75.71 \\
\hline 9 & Australia & 73.16 \\
\hline 10 & Netherlands & 72.03 \\
\hline 23 & Poland & 55.16 \\
\hline
\end{tabular}


Another area-specific study is the Global Cybersecurity Index (Global Cybersecurity Index (GCI), 2018). As the name suggests, it examines the level of cyber security. This study was created as a response to the increasing number of network users (51.2\% in 2018 with estimated $70 \%$ by 2023) and the consequent increase in the level of cyber threats. The study also points to the changes in the nature of cyber-attacks, where, in addition to the typical ransomware attacks, cyber-attacks aimed at breaching the state's critical infrastructure are becoming increasingly common. The aim of the publication is to identify weakness and areas that need improvement in order to enhance global cyber security.

The index is based on 25 indicators, which are divided into 5 pillars according to the Global Cybersecurity Agenda (GCA): legal measures, technical and procedural measures, organisational measures, capacity building and cooperation. A weight of 0.2 was assigned to each of the five factors. The results were obtained by way of a survey. The respondents were 32 specialists in the field.

Based on the results, the countries were classified into 3 groups - countries with the highest involvement, medium involvement and low involvement - according to the percentile distribution (Table 6).

Table 6. Classification of states into groups according to the Global Cybersecurity Index (Global Cybersecurity Index (GCI), 2018, pp. 14-15)

\begin{tabular}{|c|c|c|c|}
\hline groups & score level & $\begin{array}{c}\text { number of } \\
\text { states }\end{array}$ & examples of states \\
\hline \multirow{4}{*}{ high } & \multirow{4}{*}{$1 \div 0.67$} & \multirow{4}{*}{54} & United States \\
\hline & & & Russian Federation \\
\hline & & & Poland \\
\hline & & & United Kingdom \\
\hline \multirow{3}{*}{ medium } & \multirow{3}{*}{$0.669 \div 0.34$} & \multirow{3}{*}{53} & Iran \\
\hline & & & Ukraine \\
\hline & & & Pakistan \\
\hline \multirow{3}{*}{ low } & \multirow{3}{*}{$0.339 \div 0$} & \multirow{3}{*}{87} & North Korea \\
\hline & & & Somalia \\
\hline & & & San Marino \\
\hline
\end{tabular}

The results of the Global Cybersecurity Index ranking for selected state actors, along with their scores, are presented in the table below (Table 7).

Table 7. Global Cybersecurity Index - selected states ranking (as of 2018) (Global Cybersecurity Index (GCI), 2018, pp. 16, 60)

\begin{tabular}{|l|l|c|c|c|c|c|c|}
\hline \multirow{2}{*}{ position } & \multirow{2}{*}{ state } & \multirow{2}{*}{ GCI } & \multicolumn{5}{|c|}{ factor score indices } \\
\cline { 5 - 8 } & & score & legal & technic & organis & capacit & coopera \\
\cline { 5 - 7 } & & &
\end{tabular}




\begin{tabular}{|c|c|c|c|c|c|c|c|}
\hline & & index & $\begin{array}{c}\text { measur } \\
\text { es }\end{array}$ & $\begin{array}{c}\text { al and } \\
\text { procedu } \\
\text { ral } \\
\text { measur } \\
\text { es }\end{array}$ & $\begin{array}{c}\text { ational } \\
\text { measur } \\
\text { es }\end{array}$ & $\begin{array}{c}\text { y } \\
\text { buildin } \\
\text { g }\end{array}$ & tion \\
\hline 1 & United Kingdom & 0.931 & 0.2 & 0.191 & 0.2 & 0.189 & 0.151 \\
\hline 2 & United States & 0.926 & 0.2 & 0.184 & 0.2 & 0.191 & 0.151 \\
\hline 3 & France & 0.918 & 0.2 & 0.193 & 0.2 & 0.186 & 0.139 \\
\hline 4 & Lithuania & 0.908 & 0.2 & 0.168 & 0.2 & 0.185 & 0.155 \\
\hline 5 & Estonia & 0.905 & 0.2 & 0.195 & 0.186 & 0.17 & 0.153 \\
\hline 6 & Singapore & 0.898 & 0.2 & 0.186 & 0.192 & 0.195 & 0.125 \\
\hline 7 & Spain & 0.896 & 0.2 & 0.18 & 0.2 & 0.168 & 0.148 \\
\hline 8 & Malaysia & 0.893 & 0.179 & 0.196 & 0.2 & 0.198 & 0.12 \\
\hline 9 & Norway & 0.892 & 0.191 & 0.196 & 0.177 & 0.185 & 0.143 \\
\hline 10 & Canada & 0.892 & 0.195 & 0.189 & 0.2 & 0.172 & 0.137 \\
\hline 29 & Poland & 0.815 & - & - & - & - & - \\
\hline
\end{tabular}

\section{Doomsday Clock as an indicator of international security}

The Doomsday Clock is a measure of international security developed by the Bulletin of the Atomic Scientists. The level of security is represented in a symbolic way by the indication of the hour on the clock, with midnight representing the annihilation of humanity. The study has been analysing global security since 1947 till present (Fig. 2). This indicator was created to inform the public about existing global threats. The annual setting of the doomsday clock is a major media event, and is mainly addressed to: politicians, decision-makers and commentators around the world.

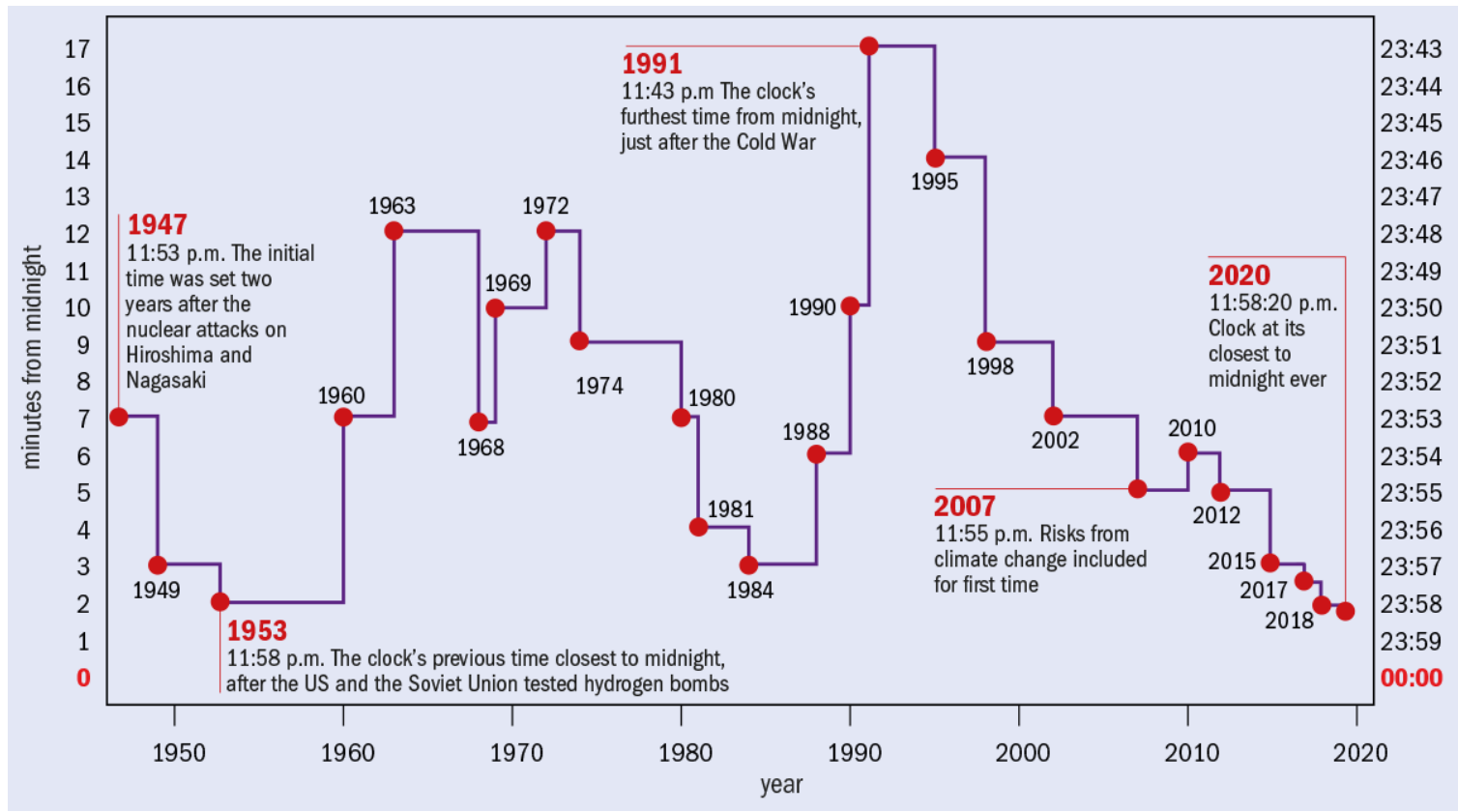


Fig. 2. Doomsday Clock indications since 1947 (Doomsday Clock ticks closer to disaster, 2020)

Since the creation of the doomsday clock till present, there have been several "tipping points" in history, when the hour hand of the clock approached midnight for such reasons as the threat of a nuclear war, climate changing technologies and the achievement of new technologies, including in the field of biology or nanotechnology.

The five consecutive changes (in 2012, 2015, 2017, 2018 and 2020), leading closer to the midnight were related to nuclear weapons - their proliferation, lack of global control over them, North Korea's underground tests and US President Donald Trump's threatening statements indicating the possibility of their use. In addition, the expiry of NPT treaties and the US withdrawal from the nuclear agreement with Iran (The Joint Comprehensive Plan of Action - JCPOA) increases the level of global nuclear threat. In addition, it should be pointed out that the states which are in possession of nuclear weapons continue to invest heavily in their development and modernisation. An example of this type of weapon under development is the Russian Avangard hypersonic cruise missile equipped with a nuclear warhead (Malinowski, 2020, pp. 91-92). Another direction in the development of nuclear weapons is being set by Asian countries. The best example is, obviously, North Korea, which is currently developing a missile equipped with a long-range nuclear warhead, the Hwasong-16 (KN-27).

The last reading of the clock on 23 January 2020 indicated 23:58:20 - 100 seconds to midnight. This has been the closest to midnight since the creation of the clock. Among the reasons for this state of affairs are not only increasing nuclear threats, but also the failure by states to take actions to protect the environment, as well as a marked increase in disinformation campaigns. One of the most serious current threats is considered to be the use of artificial intelligence (AI), which can be particularly dangerous when used in conjunction with weapons.

\section{Conclusions}

Powermetric rankings and reports provide an indication of the power of states. Due to different assumptions used in the calculation models, they present different, albeit very similar, results. In this paper, three of the powermetric studies: Global Firepower Report, 2021 Measuring National and Power Index power were analysed. The results show that the United States remains the world's largest power, with the Russian Federation, the People's Republic of China, India, Japan, France or the United Kingdom in the lead. In addition to state actors, the European Union appears to be a strong competitor to the world's largest power, the United States. 
The article reviews three studies devoted to different areas of security - health, soft power and cyber security. The first study should be considered as a valuable source of quantified information on the current situation related to the COVID-19 pandemic. The study offers knowledge on the capacity of states to prevent, detect and respond to this type of threat. It also evaluates health systems, international cooperation and the risk environment. The numerical results indicate critical points in terms of state preparedness and capacity to counter health security threats, which is generally low for most states. The second study examines soft power as a factor that is increasingly influencing international politics. High soft power skills used to achieve considerable state power are often exercised by actors with lower levels of militarisation or economic development. On the basis of the adopted model and the results of analytical research, the study identifies three possible directions of development necessary in order to maintain the international order, which include: retrenchment, consolidation and expansive reinforcement. The third study deals with cyber security. Due to the growing number of network users and the increasing level of cyber threats, this type of research will prove increasingly useful, all the more given that the nature of cyberattacks is changing and their impact on the critical infrastructure of the state is constantly increasing. The study is an encouragement for systemic analyses and a valuable source of knowledge for raising the level of security of the national cyberspace.

Another tool for measuring the level of security is the doomsday clock. It assesses the state of international security. On the basis of various types of events, it analyses and anticipates specific threats - resulting from the development of nuclear weapons, climate change, the development of new technologies and the increase in the level of disinformation. The identification of threats is the basis for taking countermeasures by individual states, especially the major world powers, in order s to maintain a high level of global security. 


\section{References}

2019 Global Health Security Index (2021). Available at: https://www.ghsindex.org/.

Arak, P. et al. (2018) State Power Index/Indeks Mocy Państw. Available at: http://ineuropa.pl/2018.

Bielawski, R. et al. (2020) 'Geopolitical Strategy of the Russian Federation in Relation to the Epicenter of the Visegrad Group on the Example of Poland in the COVID-19 Pandemic', EUROPEAN RESEARCH STUDIES JOURNAL, XXIII (Special Issue 3), pp. 2732. doi: $10.35808 /$ ersj/1850.

Boyce, M. R. et al. (2021) 'Global Fund contributions to health security in ten countries, 2014-20: mapping synergies between vertical disease programmes and capacities for preventing, detecting, and responding to public health emergencies', The Lancet Global Health, 9(2), pp. e181-e188. doi: 10.1016/S2214-109X(20)30420-4.

Doomsday Clock ticks closer to disaster (2020) physicsworld. Available at: https://physicsworld.com/a/doomsday-clock-ticks-closer-to-disaster.

Global Cybersecurity Index (GCI) (2018). Geneva: International Telecommunication Union.

Global Firepower 2021 (2021). Available at: https://www.globalfirepower.com/.

Jonathan, M. (2019) The soft power 30. A Global Ranking of Soft Power. Available at: https://softpower30.com/wp-content/uploads/2019/10/The-Soft-Power-30-Report-2019-1.pdf.

Malinowski, P. (2020) 'Hypersonic Weapon as a New Challenge for the Anti-aircraft Defense Command and Control System', Safety \& Defense, 6(2), pp. 89-99. doi: $10.37105 / \mathrm{sd} .87$.

Marklund, C. (2020) 'Soft Power', International Encyclopedia of Human Geography. Elsevier, pp. 291-296. doi: 10.1016/B978-0-08-102295-5.10706-1.

Marton, P. (2020) 'Health Security', The Palgrave Encyclopedia of Global Security Studies. Cham: Springer International Publishing, pp. 1-8. doi: 10.1007/978-3-319-743363_539-2.

Masys, A. J., Izurieta, R. and Reina Ortiz, M. (eds) (2020) Global Health Security. Cham: Springer International Publishing (Advanced Sciences and Technologies for Security Applications). doi: 10.1007/978-3-030-23491-1.

Mazarr, M. J. et al. (2016) Understanding the Current International Order. Santa Monica, CA: RAND Corporation. doi: 10.7249/RR1598. 
Mecklin, J. (2021) 'This is your COVID wake-up call: It is 100 seconds to midnight 2021 Doomsday Clock Statement', Bulletin of the Atomic Scientists. Available at: https://thebulletin.org/doomsday-clock/current-time.

Muller, J. E. et al. (2020) 'COVID-19, nuclear war, and global warming: lessons for our vulnerable world', The Lancet, 395(10242), pp. 1967-1968. doi: 10.1016/S01406736(20)31379-9.

Mutschler, M. et al. (2020) Global Militarisation Index 2020. Edited by S. Heinke. Bonn: Bonn International Center for Conversion $\mathrm{GmbH}$.

Nye, J. S. (2011) The Future of Power. PublicAffairs.

Ohnesorge, H. W. (2020) Soft Power. Cham: Springer International Publishing (Global Power Shift). doi: 10.1007/978-3-030-29922-4.

Soft Power 30 (2021). Available at: https://softpower30.com.

Szymanski, F. M. et al. (2020) 'Will the COVID-19 Pandemic Change National Security and Healthcare in the Spectrum of Cardiovascular Disease?', Current Problems in Cardiology. doi: 10.1016/j.cpcardiol.2020.100645.

Treverton, G. et al. (2005) Measuring National Power, Measuring National Power. RAND Corporation. doi: 10.7249/CF215.

USC Center on Public Diplomacy (2021). Available at: https://uscpublicdiplomacy.org/page/what-is-pd.

Uysal, N. et al. (2019) 'Turkey's Twitter public diplomacy: Towards a "new" cult of personality', Public Relations Review, 45(5), p. 101837. doi: 10.1016/j.pubrev.2019.101837.

Zhang, G. (2017) Reconstruction of Soft Power to Form Cultural Soft Power. Research Outline for China’s Cultural Soft Power, pp. 43-44. doi: 10.1007/978-981-10-3398-8_3. 